\title{
Three Approaches to Global Health Care Justice: Rejecting the Positive/Negative Rights Distinction ${ }^{1}$
}

\author{
Peter West-Oram
}

Please Note: This is the Accepted Manuscript version of a chapter published in International Development and Human Aid: Principles, Norms and Institutions for the Global Sphere (pp.108-126), edited by Paulo Barcelos and Gabriele De Angelis, and published by Edinburgh University Press. The final version of this chapter is available in that book, here: https://edinburghuniversitypress.com/book-internationaldevelopment-and-human-aid.html.

\section{Introduction}

There are two questions that we need to answer when embarking on a discussion of global duties to aid. Firstly, "What do we need to do to discharge our obligations to people in other countries?", which is a question about what needs to be done as much as it is about what duties we actually have.

The second, and more philosophically interesting, question is "Why do we have these obligations?". This relates to the reasons we have such duties and the justifications that exist for our global duties to aid. This is a prior question because the way in which we answer it will affect the way that we can answer the first question posed. Without an adequate definition of the reasons for our duties, we will struggle to provide a comprehensive description of what those duties are.

In this paper I focus on three cosmopolitan approaches to answering this second question in the context of global health care justice: Pogge's negative duties based approach (Pogge 2008: 15), Brock's minimal needs view (Brock 2009: 54-5), and Henry Shue's model of basic rights (Shue 1980: 18). While these approaches share a common focus on attempting to justify the existence of global duties to aid, held by the wealthy and owed to the global poor, each offers a distinct interpretation of why such duties exist and suggests a range of options for fulfilling them. Importantly, while I argue that Shue's approach to our global duties is the most effective of the three, I consider they all offer important insight 
into the problem of global poverty and provide a variety of possible practical solutions to this problem.

I will argue that Shue's model offers the most comprehensive justification of global duties and in fact can be seen as accommodating or incorporating the other two approaches. The efficacy of Shue's approach can be seen to have its foundation in his rejection of the positive/negative rights dichotomy. Shue's rejection of this widely, and mistakenly, held view of rights and duties is central to his argument for global duties to aid, as I discuss below. However, it is first important to explain my use of health care as an example for this paper. In the following two sections I first consider why health care should be considered an important good and go on to examine why we should consider it a question of justice.

\section{Why Health and Health Care}

Each of the approaches I consider in this paper is primarily concerned with deprivation and poverty generally, with the inequity of access to health care being considered as one issue amongst many. In this paper I concentrate on access to health care for two reasons. ${ }^{2}$ Firstly, health care can be easily recognised as a fundamental requirement of living even a minimally decent human life. Lacking health, or being unable to "access" it, through lack of access to essential health care services for example, is profoundly unpleasant at best and completely debilitating to the point of preventing enjoyment of even a basic standard of living at worst. Health care is also of importance because of its role in enabling many aspects of human life; for example, Nussbaum includes "bodily health" in her capabilities list (2003: 41-2), David Held recognises the importance of physical and mental health for democratic participation (1995: 192, 194-5), and Gillian Brock includes health in her list of requirements for human agency (2009: 66). Similarly, Henry Shue argues that health and health care are necessary for the enjoyment of all other rights (1980: 23-5).

There are those, such as Thomas Nagel, who regard the provision of basic welfare services, such as health care, as a charitable, humanitarian issue, rather than a question of justice (2005: 118). This position is based on a restricted understanding of what we should consider our obligations to those living in poverty to be, and suggests that while we should help the global poor, such action would be supererogatory, rather than simply a moral 
obligation. I shall to a certain extent assume that this position is incorrect. What I am concerned with is answering the question of why we have duties to distant others, rather than establishing exactly what they are. Of course, since I am concerned with three specific cosmopolitan justifications for our duties to aid I will implicitly argue against Nagel's more restrictive view of moral obligation, though this is not the main focus of this paper.

\section{An Example: The Global Burden of Tuberculosis}

To clarify why access to health care should be considered a question of justice it is helpful to look at the example of the global distribution of cases of tuberculosis (TB). Tuberculosis is a useful example for four key reasons. Firstly, it is a disease which is debilitating and which can kill, so we can consider the disease to have a severe adverse affect on personal welfare. Secondly, it is a disease that is both preventable and curable. Thirdly, it is a disease which is far more dangerous to people with a weakened immune system, so we can reduce vulnerability by addressing those conditions, such as malnutrition, which adversely affect general health.

This focus on general health promotion as a means of addressing the spread of tuberculosis is a key part of the World Health Organisation strategy for addressing TB (World Health Organization 2010a: 9). The argument behind these first three points is that

since the disease has a major adverse effect on personal welfare, and we are able to help those at risk of tuberculosis and those currently infected, we cannot argue that the alleviation of suffering caused by the disease is beyond existing medical and social capabilities.

A final point about tuberculosis and justice is demonstrated by the distribution of cases globally. Tuberculosis predominantly affects those living in poorer parts of the world, with roughly two-thirds of the incidences of the disease occurring in Africa and South-East Asia (World Health Organization 2010b). Wealthier countries, such as the United States and the UK, are relatively unaffected by comparison (World Health Organization 2010b). This disparity is important because it suggests that there is something that rich countries are doing that poor countries are not, which means that they are less affected than they would be otherwise. In itself this may not be a compelling reason to regard access to health care as an issue of justice. However, when we consider Pogge's (2008: 118-20) arguments 
on the impact of large scale economic activity in exacerbating global poverty, the disparity in incidences of tuberculosis seems more likely to be a possible case of injustice. In line with Pogge's thinking generally about wealth disparities, and the causal role wealthy countries have in exacerbating them, the disparity of tuberculosis incidence rates between rich and poor countries may indicate that poor countries are unable to replicate certain conditions that keep these rates low in wealthier countries. Therefore, by exacerbating poverty, wealthy countries may be encouraging, or at least allowing, the circumstances in which diseases like tuberculosis can thrive. In the following section I examine the first of the three approaches to global justice that this paper is concerned with; Thomas Pogge's negative duties based approach.

\section{Approach One: Pogge's Negative Duties Approach}

Pogge's argument is based on the claim that there is a negative duty not to cause harm. He accepts, at least for the purposes of his argument, the negative view of rights and attempts to provide a justification for global duties of aid based on the empirical claim that the actions of agents in wealthy nations are in fact causing harm to the poor through economic, social and diplomatic practices, so that these agents are failing in their duties not to cause harm (Pogge 2008: 148-50). ${ }^{3}$ For the purposes of this paper I shall assume that all of Pogge's claims about the harmful effects of the actions of wealthy nations are correct and that we are actually causing harm to the global poor through our actions. Pogge offers a variety of examples of the ways in which the actions of the wealthy affect the global poor. However, it is not the empirical data which concerns me, but rather the basis of his philosophical position which seems to leave him vulnerable to a problematic objection.

Pogge's argument is almost deceptively simple; there is a duty not to harm, currently we (in wealthy countries) do harm people, and therefore we fail in our duty. Therefore, to fulfil our duty not to harm we must change our behaviours. In the case of tuberculosis, we could say that since our actions encourage poverty, we restrict the extent to which poor countries can provide their citizens with adequate social services and so encourage the conditions in which tuberculosis and diseases like it thrive. Therefore, we are failing in our duty not to cause harm by encouraging poverty and hence disease so we 
must refrain from certain behaviours and increase our proactive involvement in activities which address global poverty and deprivation.

There are three main options open to those who would criticise Pogge's argument.

Firstly, there are two type of possible empirical objection, which Pogge acknowledges, and I believe, successfully rejects. Specifically, there are those criticisms that deny the causal responsibility of wealthy nations for conditions in poor countries (Pogge 2008: 12-15), and there are those that accept causal responsibility but deny that there is a better alternative available (6-11). ${ }^{4}$

An example of the case of the first objection can be found in John Rawls' The Law of Peoples, where he states that conditions in poor countries are likely to be the result of “oppressive governments and corrupt elites” (Rawls 1999a: 77; Pogge 2008: 295, fn238). This claim may be partially correct, corruption and oppression can hardly be thought to be to the benefit of the global poor. However, as Pogge notes, this explanation ignores the role that wealthy countries have in supporting those governments and elites, and the responsibility that obtains as a result of such support. As such, the claim is hard to substantiate given the range of examples offered by Pogge of the impact that the actions of wealthy nations can have on the global poor (2008: 118-22, 148). Similarly, Leif Wenar has drawn attention to the impact that our engagement through trade with authoritarian regimes in resource-rich countries actively harms the citizens of such countries by depriving their citizenry of resources which should be used for their benefit (Wenar 2008: $3-4)$.

The more subtle claim, that there is no better alternative to the existing world order, may be based on a variety of empirical arguments. For the purposes of this paper I shall briefly consider two of these possible approaches. Firstly, as Pogge notes (2008: 9-10), it may be objected that the cost of helping the poor achieve a higher standard of living would impose such hardship on the wealthy that the outcome would be worse than the current global situation in terms of overall welfare (Rorty 1996: 14-16). Secondly, as Pogge also recognises (2008: 7-9), it may be argued that by helping the poor we inadvertently contribute to the worsening of everyone's long term welfare. See, for example, Garrett Hardin's article "Living on a Lifeboat" (1974) in which he argues that rapid population growth will lead to the inevitable exhaustion of the world's natural resources and hence a 
far greater loss of general welfare (and life) than would be the case if we maintain our current position of not helping.

The first of these claims - that by attempting to improve the lives of the global poor we may be forced to drastically and unjustifiably reduce our own standard of living - Pogge argues is simply mistaken; the cost of massively improving the lives of the global poor is not so vast as to damage the welfare of the wealthy. For example, Pogge states that the cost to wealthy countries of lifting the 950 million people around the world out of extreme poverty and into the "higher" economic category of "severe poverty" would cost roughly \$38 billion annually. A large sum certainly, but the impact on wealthy countries would, according to Pogge, reduce "our share from 78.98 percent of the global product down to 78.90 percent" (2008: 105), hardly an immense loss.

Pogge also provides a convincing argument against the "population explosion" argument suggested by Hardin. Hardin's argument may initially seem convincing; drawing attention to the great difference between population growth rates in wealthy and poor countries, ${ }^{5}$ he raises concerns about the sustainability of such rapid population growth in a world of scarce resources. However, as Amartya Sen has argued (1994), there is an inverse correlation between improved economic status and population growth; that is, when income and welfare go up, the birth rate decreases. To argue that rapid population growth is a threat to everybody, and that the preventable deaths of millions are in some way necessary, is to ignore significant empirical data which demonstrates the exact opposite of what is argued: that alleviating poverty is an effective way of controlling population growth.

Pogge counters the empirical objections to his argument, but it is a philosophical question that presents a more troubling problem for his position. Pogge explicitly argues that "human rights entail only negative duties" (2008: 72). By rejecting any positive interpretations of duties, Pogge ignores a significant aspect of human rights as there will inevitably be cases where merely refraining from harmful action will be insufficient to guarantee the entitlements provided by a human right. Even if we accept the argument that Pogge's position demands that we not be passive bystanders to injustice, as I think we should, this can readily be interpreted as a positive demand for action, rather than a negative demand for passivity in the face of opportunities to harm. 
Further, and perhaps more problematically for Pogge, the ease with which it is possible to rephrase certain "negative" duties as "positive" requirements highlights the inadequacy of a purely negative model of duty. Even if one acknowledges that Pogge's argument demands that we must actively engage with making global institutions just, this seems to be an obviously positive duty and one which his approach is ill-suited to account for. It seems to be the case that Pogge's account of duty does actually imply positive duties, but in explicitly stating his support for a "negative duties alone" model (2008: 26) Pogge leaves himself without the right tools to include the positive steps needed to facilitate those duties.

Further, focusing purely on negative duties ignores the importance of assistance after harms have occurred, and cases where a person has suffered significant damage to their welfare through brute bad luck, rather than the actions of any identifiable agent. I shall call this the "sorry but..."-argument. This claim would allow opponents of duties to the global poor to acknowledge that harm has been done, but then to deny that they have any responsibility to actually do anything to help as they were not responsible for the harms caused. For example, such an argument could accept that we should refrain from harming, but deny that there is a corresponding duty to help, as such an obligation would be a positive duty and as such would be an unwarranted restriction on liberty. ${ }^{6}$

This is difficult to address within Pogge's framework precisely because he explicitly accepts the negative rights view, and thus gives too much space for his opponent to reject all non-negative duties. Therefore, even though for Pogge the duties are negative, they clearly contain significant positive elements which cannot be accounted for under Pogge's model and which weaken the claim that human rights and justice require only negative duties. If one does not accept the existence of duties to the global poor, or if one is committed to a purely negative view of those duties, it is far too easy, on acceptance of Pogge's view, to reject essential demands of human rights as being beyond the scope of negative duty. Thus his argument is vulnerable to an objection grounded on the same foundations as his own - the negative view of duties.

As I have stated above, Pogge successfully rejects the empirical objections to his position. However, by embracing a "negative duties only" model, he does not seem to be able to account for the full range of duties demanded by human rights. Before I discuss this 
problem in more detail I will first examine the second of the three approaches to global justice that I am concerned with in this paper, Brock's minimal needs approach.

\section{Approach Two: Brock's Minimum Entitlements Approach}

Where Pogge approaches a justification of our global duties using a negative duty not to harm, Gillian Brock is primarily concerned with meeting basic needs. She proposes a minimum threshold based approach which is reminiscent of the argument presented by Peter Singer in "Famine, Affluence, and Morality" (1972) in that she argues that since we are able to lift those living in severe poverty above a minimum acceptable welfare threshold at little cost to ourselves, we have an obligation to do so.

Brock's focus is on shared fundamental human needs, including things such as certain basic liberties and protection from common causes of harm (2009: 52). These basic needs, Brock argues, should concern us as a matter of justice because they are so fundamental to living an autonomous human life that those without them do not enjoy even a minimally acceptable welfare standard.

While Brock's conclusion is similar to that offered by Singer, her justification for that conclusion is profoundly Rawlsian, based as it is on a variation on the original position which Brock calls the "ideal choosing situation" (2009: 52). Brock argues that in the ideal choosing situation, which includes a modified veil of ignorance, participants would select a minimum threshold model as the fairest way to guarantee an acceptable welfare standard for all persons. Such a solution would be just, she argues, because it represents a rational choice for persons to make as it offers a broader set of guarantees, compatible with all views of the good, than those suggested by Rawls as arising from the original position.

Brock reinforces her argument with reference to empirical studies conducted by Frohlich and Oppenheimer (1992) which confirm the results of the thought experiment. In these studies, which were conducted internationally, participants from a variety of cultural backgrounds were asked to select a just system of guaranteeing individual welfare from four options. Importantly, the studies were conducted under similar conditions to those endorsed by Brock in her ideal choosing situation, with particular emphasis on "conditions of impartiality" (Brock 2009: 54). The four options available included: firstly, a Rawlsian difference principle (Rawls 1999b: 65) for maximising the income of the worst off; 
secondly, a principle to maximise the average income, following Harsanyi (1953); thirdly, a principle "maximising the average with a floor constraint of \$_ "; and, finally, a principle which maximised "the average with a range constraint of \$__ (Brock 2009: 54-5). Overwhelmingly, a safety net or minimum threshold model (the third option) was selected as the most just or fairest way of guaranteeing individual welfare (Brock 2009: $55)$.

As with Pogge, I think Brock's argument has considerable force and covers much ground that Pogge does not. However, I do have a concern with one consequence of Brock's focus on individual needs and a minimum acceptable welfare standard: it is difficult following Brock to assign responsibility to specific persons, an advantage that Pogge, and Shue, have over Brock. This is perhaps not terribly problematic as we can readily assign responsibility through reference to our shared needs or a reciprocity agreement. "Why me?" can be answered "because you would get the same help if you were in their place". And, of course, institutions play a key role in actual distributions, so their role in facilitating existing deprivations as well as potential solutions should not be overlooked as a basis for justifying their obligations to help. However, reciprocity and empathy are not the best justifications for duties to aid available to us. For reciprocity we must answer concerns about duties to those who cannot reciprocate, and empathic arguments depend on acknowledging that we would have a duty to help in the first place, something that many governments and individuals are of course notoriously unwilling to consider.

\section{Defining the Problem}

As mentioned above, Pogge's acceptance of the negative view of duties presents significant difficulty when attempting to justify certain kinds of positive action, such as providing aid to the deprived. In contrast, as I discuss below, Shue rejects the classification of rights and duties as being either positive or negative and can therefore justify a wider range of moral obligations than is available to Pogge. Brock's focus on individual needs, derived from a variation of the original position avoids the problem of justifying positive action by emphasising the importance of certain social goods. However, Brock's position presupposes that others will share her recognition of the need to guarantee these goods, and it is by no means clear that such recognition is widespread. Therefore, it is 
difficult for Brock to make demands of specific agents as she does not provide a comprehensive justification of who should do what. By comparison, Shue can justify a much closer link between specific agents and positive behaviours, because he adopts a rights based approach, thereby implying the assignation of duties, but he rejects the negative/positive distinction which creates such problems for Pogge. In the rest of the paper, I argue that Shue's approach provides the kind of comprehensive argument necessary for a full justification of global duties to aid.

\section{Approach Three: Shue and Basic Rights, Rejecting the Positive/Negative}

\section{Rights Distinction}

As mentioned in the previous section, there are a variety of problems associated with the justifications of our global duties offered by Pogge and by Brock. Each has its own difficulties, but they share a common issue in that both models assume the validity of the distinction between positive and negative rights and duties. This distinction is based on the claim that there is a significant difference between positive rights, which entitle rights holders to demand that others perform certain actions, and negative rights, which entitle the holder to demand that duty bearers refrain from certain behaviours.

Contrary to this, Henry Shue claims that there is no basic right which can be classified as either positive or negative. As such, arguments which rest on the assumption that the positive/negative distinction is correct will present an incomplete picture of the kinds of duties that are required for global justice.

Shue describes three categories of basic rights: to security, to subsistence and to liberty. Each of these basic rights is made up of various constitutive elements. Thus, the right to security includes rights to protection from harm and against theft of one's property; the right to subsistence contains rights to things like adequate nutrition, sanitation and basic health care; and the right to liberty contains rights to personal freedoms, such as self determination and political participation. Shue considers these rights to be fundamental prerequisites for the enjoyment of any other rights; they are basic because without them, according to Shue, we cannot have any rights at all. In this way he shares similarities with both Pogge and Brock. Like Pogge he derives his argument about duty from a logical extension of what it means to have a right, but like Brock his concern is for establishing a 
minimum threshold of entitlement. These rights are basic according to Shue not only because they enable the enjoyment of other rights, but also because they guarantee the ability to have a "decent life" (1980: ix).

It is important to note that as well as being necessary for non-basic rights, each of the three basic rights is dependent on each of the others: the enjoyment of security depends on our enjoyment of liberty and subsistence rights, etc. For example, we cannot enjoy a right to liberty if we are starving to death, no more than we can if we must risk being assaulted in order to vote. Similarly, a right to security or to subsistence is worth little if we are at the mercy of some temporarily "benevolent dictator" (Idem: 74-5) as Shue puts it. Each of the basic rights cannot therefore be classified as either positive or negative, their interdependence demands both that we are guaranteed protection from and assistance in the case of certain harms, just as they also entitle us to demand that others not perpetrate certain acts against us; positive and negative demands respectively. "It is impossible" Shue argues "for any basic right - however 'negative' it has come to seem - to be fully guaranteed unless all three types of duties are fulfilled" (53).

For example, the right to political participation, itself one aspect of the right to liberty, entails both negative and positive requirements. The entitlement to vote, or to engage in political protest, obviously requires that rights holders not be subject to violence or intimidation when attempting to cast their ballot, so there is a negative duty not to attempt to limit a person's entitlement to participation through such means. But the right also requires that laws and the means to enforce them exist so that rights holders are protected from "those who do not choose not to violate [the right to political participation]" (39). The right to political participation therefore requires both negative and positive duties. It is simply not enough that we not perform certain actions; we also have to ensure that those who would choose to restrict the rights of others are unable to do so (61). Fulfilment of the "positive" condition of the right to liberty can be constructed as a duty to contribute fairly to taxation so that the means of law enforcement are funded in such a way as to be able to enforce the duties relating to a specific right. Of course, the creation and maintenance of a system of laws also demands the existence of a duty to contribute fairly through taxation. 
This rejection of the positive/negative rights distinction is central to Shue's argument, and is the theoretical foundation which allows him to offer a more comprehensive position than either Pogge or Brock. By arguing that rights require both positive and negative duties Shue can avoid Pogge's difficulty with justifying positive action and assign responsibility to specific agents more effectively than Brock.

To account for the broad requirements of the interrelated basic rights Shue offers the following "tripartite" (53) model of duty, which includes both positive and negative requirements.

"I. To avoid depriving.

II. To protect from deprivation

1. By enforcing duty (I) and

2. By designing institutions that avoid the creation of strong incentives to violate duty (I).

III. To aid the deprived

1. Who are one's special responsibility,

2. Who are the victims of social failures in the performance of duties (I), (II-1), (II-2) and

3. Who are the victims of natural disasters."

(Shue 1980: 60)

Like Pogge, Shue includes a proscription against harming (or depriving) under duty one, and like Brock, he recognises the importance of basic needs by demanding a duty to aid under duty three. Importantly, duty two offers an intermediate step between the other two and serves to support the duty not to cause harm. This duty recognises the existence of harms that we can prevent or at least minimise the risk of their occurring and to enforce the duty to avoid depriving. Importantly, according to Shue, each of the duties can be held by both individuals and institutions, though the requirements may vary according to the agents (60-1).

\section{The Implications of Shue's Model for Health Care}


If we relate this model to health care we can see that Duty One would require us to avoid behaviours likely to cause harm, drunk driving for example. Looking beyond individuals, the way that the TRIPS regime within the pharmaceutical industry excludes the poor from essential medicines is an example of corporate or governmental failure to meet the duty to avoid depriving. ${ }^{7}$

The TRIPS regime is problematic for the latter two of Shue's three duties, but it also violates the duty to avoid depriving. Prior to the advent of the TRIPS regime, manufacturers of generic medicines in countries such as India could work under domestic patent laws which allowed the production of generic drugs by providing patents only on processes rather than products. This allowed manufacturers to develop generic versions of drugs for sale to those who would be unable to afford the monopoly prices demanded for branded medicines (Barton 2004: 147). In contrast, TRIPS provides patents for products rather than processes, meaning that generic manufacturers are now unable to offer generic versions of drugs which are still under patent. ${ }^{8}$ The effect of this change is that the TRIPS regime has deprived the global poor of their main source of essential medicines by rendering the process by which affordable medicines are created illegal (Barton 2004: 149$52)$.

The second duty requires that both individuals and institutions contribute fairly to the maintenance of health promoting or protecting institutions, for example a duty to pay our fair share of the tax burden to ensure that adequate sanitation is provided to all people. Similarly, the duty to protect also implies the existence of meaningful laws which enforce the duty to avoid depriving and reduce the likelihood of risks to health occurring in the first place.

Shue acknowledges that in a world of perfect beneficence, where everyone fulfilled their duty to avoid depriving, there may be less need for a duty to protect (1980: 61). However, he rejects this possibility as unrealistically utopian and argues that while people and corporations may restrain themselves under threat of the law, they are far less likely to do so when not so restricted. Accordingly, Shue argues that a duty to protect is necessary to ensure good behaviour by those who may cause harm (61). In the case of the right to health care, as with other rights, while perfect beneficence and adherence to duty might be 
theoretically possible, it is extremely unlikely, so the relevant laws and regulations are necessary as a matter of practicality.

The duty to aid most closely corresponds to Brock's argument. It is a duty to ensure that in cases where we were unable to prevent harm those affected are not ignored or left to die. In the case of health care this duty would require the provision of treatment for disease or injury. Similarly, the duty would require the provision of support in terms of sanitation, sewerage, and nutrition to those affected by natural disasters.

Like the three basic rights, Shue's three duties are interconnected, so a right which did not entail the fulfilment of all three types of duty would lack significant force. In the absence of the duty not to harm, the duty to protect could soon be overwhelmed by the needs of those harmed by the actions of the malevolent or negligent. Similarly, in the absence of the duty to protect, the right not to be harmed would become dependent on luck, while the duty to aid would face far greater demands, prevention being better, and usually cheaper, than cure. Finally, refusing a duty to aid overlooks the fact that duties are often ignored and that poor luck can have consequences as bad, if not worse, than malicious action. As such, ignoring an obligation to provide aid would turn the duties to avoid depriving and to protect into the worst kind of threshold, one which merely described a line beneath which the unfortunate were condemned to struggle.

\section{Resolving the Problem}

I mentioned above that the main concern I have with Pogge's justification of global duties to aid arises because of his acceptance of the negative view of rights and duties. This view holds that moral duties can only demand that we refrain from engaging in certain types of behaviours, ${ }^{9}$ and, as such, Pogge's acceptance of the view makes it difficult for him to move from responsibility for harms to any demands for positive action. In contrast, Brock's focus on individual needs provides a sound justification of why certain goods, such as health care, are important, because they enable human agency (2009: 66). However, her model does not provide as convincing an argument as to why specific agents have a responsibility to guarantee access to those goods as that provided by Shue. Shue's approach offers a stronger argument for assigning duties as well as a way to avoid the problems of positive duties associated with Pogge's position. 
Shue recognises the importance of a duty to avoid harming, but he makes no claim that this is based on a negative model of rights; it is simply a requirement of having a right that others not violate it. So he can account for Pogge's approach here. Similarly, Brock's approach can be accounted for by Shue's acknowledgement of the significance of positive action. We have to have some duty to protect and to aid, else the duty not to harm really does become as Shue puts it "the only poison they [the vulnerable] need" (1980: 19). The interrelatedness of Shue's three basic rights is fundamental to his argument and provides the basis for his rejection of the positive/negative rights distinction, itself an integral part of Shue's argument. By emphasising the relationship between the three basic rights, and arguing for the necessity of both "positive" and "negative" duties in his tripartite account of duty, Shue can place a wider range of obligations on duty bearers by drawing attention to the need for active, "positive" engagement in the fulfilment of rights, such as the right to liberty, which are frequently, and mistakenly, thought of as purely negative rights.

Furthermore, he can also make claims about responsibility in a stronger manner than Brock, because he grounds his argument in an analysis of rights and argues that we have to have rights to certain things if we are to have any rights at all. By doing so he can point at a right to life (or the kind of goods that he and Brock are both concerned with) and demand "do you think that we have this?". ${ }^{10}$ If the answer is yes, then we are committed at least to his framework of basic rights. If the answer is no, then it seems that the respondent is suggesting some kind of Hobbesian state of nature where no rights were guaranteed, which seems, at least intuitively, inherently unsatisfying.

\section{Conclusion}

My aim in this paper has been modest. I do not wish to assert that either Pogge's or Brock's argument is untenable or should be ignored. Much can be learned from both positions and both offer a significant contribution to a comprehensive approach to global justice. Pogge's “Global Resource Dividend” (Pogge 2008: 202), and his involvement in the development of the "Health Impact Fund" (Hollis and Pogge 2008; Bannerjee et al. 2010), as well as Brock's “Global Justice Fund” (Brock 2009: 136), offer excellent practical suggestions for addressing global poverty. However, neither Pogge nor Brock can offer a fully satisfying argument for the existence of our global duties to aid. Pogge's 
account gives too much to the neo-liberal position by tacitly accepting that we should only view negative duties as having any weight, and by doing so he allows room for a critic to argue that because we only have negative duties we are only under obligation to stop harming, something which can be interpreted minimally, and not to actually help. In contrast, Brock's position can offer an argument as to why someone should help, but a much weaker explanation of why any specific agent should help than can be provided under Shue's model.

Shue meanwhile does give us a reason to care about a minimum threshold, and provides explanation of why specific agents should consider themselves responsible. For Shue, the varied responsibilities under his tripartite account of duty can be assigned to everyone, because that responsibility is simply a requirement of the existence of rights. Exactly what those responsibilities are will vary according to the agent specific context, which may include factors such as ability, culpability and relationship to the specific right holder. However, while the specifics of how rights are to be fulfilled may vary, we can readily assign general duties to specific agents in a far simpler manner than is available to Brock. Where Brock must move from a need based model to duty, Shue works within the model of rights and duties and challenges mistaken preconceptions about them. Thus, Shue has a much simpler path to the assignation of specific duties.

Neither Pogge nor Brock offers a full justification of our duties to aid. They offer partial solutions, and each of them is vulnerable to the questions I have set out. In contrast, if we follow Shue's approach, we are provided with a comprehensive argument which avoids the objections simply by rejecting the classification of rights and duties as positive or negative. And this is the key strength of Shue's argument - by rejecting the false dichotomy of positive/negative rights he removes a significant argument against duties to aid, that we have only negative duties. By classifying rights as having a broader set of requirements than what would be allowed under a purely negative model, Shue demands that if we acknowledge a right to anything, we must fulfil certain positive and negative obligations. We cannot deny a duty simply because it is positive and hence too demanding, because to do so turns rights and duties into meaningless decoration used to disguise the fact that such "quasi-rights" offer no more protection than being lucky enough to avoid disease or violence. 
Rejecting the positive/negative distinction enables us to justify a better system of rights and duties relating to health care or to other issues of justice than is available if we follow either Pogge or Brock's approach. If the foundation of Shue's argument is that if we have a right to something we must also have a right to the things necessary for it, the framework of the argument is that to classify a right as either positive or negative is simply to misunderstand what a right is. In the case of health care, declaring that we have a right only to non-interference means only that we are free to die of the first disease that is severe enough. If we only have a right to protection, then we only have a right to health care until that protection fails, if we catch some unpreventable disease, or are in a car accident we are on our own. Finally, if we have only a right to assistance, then we are entitled to help, but that help can at best restore us to health and not compensate us for being harmed in the first place. And, in any case, even if we are returned to full health, we have still been harmed, and a reason to think health is important is because lacking it can be catastrophic. Any actual basic right must entail a comprehensive set of corresponding duties beyond mere non-interference if it is going to be worth anything, and Shue's approach offers the best way of justifying such duties.

\section{References}

Bannerjee, Amitava, Aidan Hollis \& Thomas Pogge (2010), The Health Impact Fund:

Incentives for Improving Access to Medicines. The Lancet, N. 375, p.166-169.

Barton, John H. (2004), TRIPS And The Global Pharmaceutical Market. Health Affairs, Vol. 23, N.3, pp.146-154.

Brock, Gillian (2009), Global Justice: A Cosmopolitan Account (Oxford: Oxford University Press).

Frohlich, Norman \& Joe Oppenheimer (1992), Choosing Justice: An Experimental Approach to Ethical Theory (Berkeley and Los Angeles: University of California Press). Hardin, Garrett (1974). Living on a Lifeboat. Bioscience, Vol. 24, N. 10, pp.561-568. 
Harsanyi, John C., 1953. Cardinal Utility in Welfare Economics and in the Theory of Risk-taking. Journal of Political Economy, Vol. 61, N. 5, p.434-435.

Held, David (1995), Democracy and the Global Order: From the Modern State to Cosmopolitan Governance (Oxford: Polity Press).

Hollis, Aidan \& Thomas Pogge (2008), The Health Impact Fund: Making New Medicines Accessible for All. A Report of Incentives for Global Health. Available at:

http://healthimpactfund.org/hif_book.pdf [last accessed October 22, 2012].

Hubbard, Tim \& James Love (2004), A New Trade Framework for Global Healthcare

R\&D. PLoS Biology, Vol. 2, N. 2, pp.147-150.

Nagel, Thomas (2005), The Problem of Global Justice. Philosophy and Public Affairs, Vol. 33, N. 2, p.113-147.

Nussbaum, Martha (2003), Capabilities As Fundamental Entitlements: Sen And Social Justice. Feminist Economics, Vol. 9, N. 2-3, p.35-59.

Pogge, Thomas (2008), World Poverty and Human Rights, Second Edition (Cambridge, UK: Polity Press).

Rawls, John (1999a), The Law of Peoples; with, The Idea of Public Reason Revisited, (Cambridge, Mass: Harvard University Press).

Rawls, John (1999b) A Theory Of Justice: Revised Edition, Revised Edition (Cambridge, Mass: Harvard University Press).

Rorty, Richard (1996), Who Are We?: Moral Universalism and Economic Triage.

Diogenes, Vol. 44, N. 173, pp.5-15.

Sen, Amartya (1994), Population: Delusion and Reality. New York Review of Books, Vol. 41, N. 15, pp.62-71.

Shue, Henry (1980), Basic Rights: Subsistence, Affluence and U.S. Foreign Policy

(Princeton, N.J.: Princeton University Press).

Singer, Peter (1972), Famine, Affluence, and Morality. Philosophy and Public Affairs, Vol. 1, N. 3, p.229-243.

Wenar, Leif (2008), Property Rights and the Resource Curse. Philosophy and Public Affairs, Vol. 36, N.1, p.2-32. 
World Trade Organization, 1994. Annex 1C: Agreement on Trade Related Aspects of

International Property Rights, Available at:

http://www.wto.org/english/docs_e/legal_e/27-trips.pdf [last accessed October 22, 2012].

World Health Organization, 2010a. Global Tuberculosis Control: WHO Report 2010,

WHO Press. Available at:

http://www.doh.state.fl.us/disease_ctrl/tb/Trends-Stats/Fact-Sheets/US-

Global/WHO_Report2010_Global_TB_Control.pdf [last accessed October 22, 2012].

World Health Organization, 2010b. WHO Tuberculosis: Fact Sheet No. 104. WHO:

Tuberculosis. Available at:

http://www.who.int/mediacentre/factsheets/fs104/en/index.html [last accessed October

22, 2012].

${ }^{1}$ I am deeply grateful to Professor Heather Widdows (the University of Birmingham), the participants and organisers of the "Global Economic Justice: Assessing International Aid" conference, held at the Universidade Nova, Lisbon, Portugal, and to Patrick Andelic for their very helpful comments on an early draft of this paper. In addition, I am grateful to the U.K. Arts and Humanities Research Council (AHRC) for their generous financial support whilst writing this paper.

${ }^{2}$ It may be objected that since health is the objective of health care, we should talk in terms of access to health rather than health care. This is a profoundly complicated question and I do not wish to go into it here, instead I shall use the term "health care" in a very loose sense, and leave discussion of whether we have a right to health or health care for another time.

${ }^{3}$ I take "agents" to include individual persons, corporations, as well as governments.

${ }^{4}$ Pogge refers to these arguments as "easy reasons to ignore world poverty" (Pogge 2008: 6)

${ }^{5}$ At the time Hardin's article was published population growth in wealthy countries was at a rate that would double the population every 87 years, while the same effect in poor countries took only 35 years (Hardin 1974: 564).

${ }^{6} \mathrm{I}$ discuss this issue in greater detail in sections seven and eight below.

${ }^{7}$ The Trade Related Aspects of Intellectual Property Rights (TRIPS) regime is an agreement between member states of the World Trade Organization which provides guaranteed monopolies to the creators of certain kinds of intellectual property, including; trademarks, industrial designs and patents (World Trade Organization 1994: 319). Importantly, the TRIPS agreement also provides protection for pharmaceutical products, thus granting patent holders a monopoly on the production and sale of potentially life saving drugs. TRIPS has been widely criticised, both for its alleged ineffectiveness (Hubbard \& Love 2004), and for the way that it allows pharmaceutical companies to charge extremely high prices for medicines which may make them inaccessible to those with insufficient funds (Barton 2004: 149-50; Hollis \& Pogge 2008: p.1).

${ }^{8}$ Of course, it may be objected that what is relevant in this case is that the original producer of drugs loses out on a potential market for their products if other companies can manufacture generic versions of their 
products and undercut them on price. However, we should remember that the people who are most in need of cheap drugs and who have been most harmed by the limitations placed on their production are the same people who would simply not have been able to purchase brand-name drugs in the first place. Given the inability of the global poor to pay monopoly prices for brand name drugs, a market which caters to their unmet needs, such as the Indian generic pharmaceuticals industry, does not remove a potential or former market for pharmaceutical companies; rather it provides the benefits of medical technology to those who would otherwise not have been able to benefit from it. Hollis and Pogge discuss this in more detail in The Health Impact Fund: Making New Medicines Available for All (2008: 64-66).

${ }^{9}$ As opposed to legal duties which may involve positive obligations.

${ }^{10}$ Shue and Brock share a sufficientarian concern with establishing a minimum threshold of entitlement to certain basic goods. However, where Brock writes in terms of goods, Shue is focused on rights and duties, another reason it is easier, using his approach, to assign responsibility to specific persons. 